Tuğba Düzenli, Sema Mumcu, Abdullah Çiğdem

Karadeniz Teknik University, Trabzon-Turkey

tugbaduzenli@gmail.com; semamumculktu.edu.tr; abdullahcigdeml@gmail.com

\begin{tabular}{l|l|l}
\hline DOI & \multicolumn{2}{|c}{ http://dx.doi.org/10.12739/NWSA.2018.13.4.3C0176 } \\
\hline \multirow{2}{*}{ ORCID ID } & $0000-0001-6957-3921$ & $0000-0002-5198-9117$ \\
\cline { 2 - 3 } & $0000-0002-6468-3600$ & Tuğba Düzenli \\
\hline \multicolumn{2}{l}{ CORRESPONDING AUTHOR } &
\end{tabular}

\title{
PEYZAJ MIMARLIĞI EĞİTIMİNDE OTURMA DONATISI TASARIMI: KTU PEYZAJ MİMARLIĞI BÖLÜMÜ ÖRNEĞİNDE İNCELENMESİ
}

Öz

Bu çalışmada Peyzaj Mimarlığı bölümü eğitiminde ergonomik ve özgün donatılar tasarlatmayı amaçlayan Donatı Tasarımı dersinde yapılan oturma birimi maketleri değerlendirilmiştir. Karadeniz Teknik Üniversitesi Peyzaj Mimarlığı Bölümü 3. Yarıyıl derslerinden olan "Donatı Tasarımı" dersi bu amaçla incelenmiştir. Bu ders kapsamında öğrenciler; mekan ile donatı arasındaki uyumu yaratmayı, donatıların hem fonksiyonel hem de estetik açıdan nasıl tasarım sürecinde kullanılabileceğini öğrenmektedirler. Dersin ana amacı donatı elemanlarının mekanla bütünleşerek mekana kimlik katabilmesinin öğrenciye öğretilmesidir. Çalışmada 2017 yılında bu ders kapsamında öğrencilerin yaptığı oturma birimi maketlerinde donatı çözümleri analiz edilerek ölçü-biçim-yaratıcılık açısından incelenmiştir. Sonuçta öğrencilerin, ölçü ve etkinliğe uygun ölçüde farklı biçimlerde yaratıcı oturma donatıları tasarlayabildikleri belirlenmiştir.

Anahtar Kelimeler: Donatı Tasarımı, Oturma Donatısı, Ölçü, Peyzaj Mimarlığı Eğitimi, Trabzon

\section{SEATING EQUIPMENT DESIGN IN LANDSCAPE ARCHITECTURE EDUCATION: INVESTIGATION OF THE CASE OF KTU LANDSCAPE ARCHITECTURE DEPARTMENT ABSTRACT}

In this study seating equipment models that were produced in Equipment Design course which aims to teach designing ergonomic and unique equipment's in landscape architecture curriculum are evaluated. To this end "Equipment Design" course in the third term of Karadeniz Technical University, Landscape Architecture Department curriculum is discussed. This course which is selective aims to teach students how equipment-space compatibility can be achieved and how equipment's can be dealt with in design process in terms of functional and aesthetic aspects. The main goal of this course is to teach how spatial identity can be established by integrating equipment elements with the space, with each other and with the activity type that they serve. In this study the seating equipment's designed and produced by students in context of this course conducted in year 2017, were analyzed in terms of size, shape and creativity solutions. The students were requested to design a seating equipment and produce a model of it with 1/20 scale. Models made by students were analyzed in size, shape and creativity. As a result, it was revealed that students can design seating equipment's that are suitable for size and function, differ in size and creative in shape.

Keywords: Equipment Design, Seating Equipment, Measure, Landscape Architecture Education, Trabzon

How to Cite:

Düzenli, T., Mumcu, S. ve Çiğdem, A., (2018). Peyzaj Mimarlığı Eğitiminde Oturma Donatısı Tasarımı: KTÜ Peyzaj Mimarlığı Bölümü Örneğinde İncelenmesi, Social Sciences (NWSASOS), 13(4):126-134, DOI:10.12739/NWSA.2018.13.4.3C0176. 


\section{GÍRIŞ (INTRODUCTION)}

Donatı elemanları, kullanıcılar arasında toplumsal iletişimi sağlayan, mekana kimlik katan, mekanı tanımlayarak hem estetik hem fonksiyonel açıdan kullanım imkanı sunan nesnelerdi. Bundan dolayı yalnız fonksiyonel değil mekanı yaşanabilir kılması açısından da çok önemlidir (Güney vd., 1996). Mekanın bir parçası olarak tasarlanan donatılar bir system oluşturmalıdır. Mekan-etkinlik-donatı arasında bir uyum olmalı, hepsi bir arada hareket etmelidir (Harris ve Dines, 1998). Kullanıcı ihtiyaçlarına cevap vermesi gereken donatılar, uygun ölçülerde ve özelliklerde olmalıdır (Celbiş, 2001; Molnar, 2015). Donatı elemanları mekansal kimliği yansıtırken, kullanıcıları fiziksel ve psikolojik açıdan da rahatlatabilmektir (Yücel, 2006; Bayraktar vd., 2008). Kullanıcı ile kullandığı mekandaki donatılar bir sistem olarak ele alınmalı ve aralarında uyum sağlanmalıdır (Yıldırım, 2000). Günümüzde oturma donatıları insanların yaşamlarının bir parçası haline gelmiş, en yoğun kullanılan donatı türüdür. Bu nedenle peyzaj mimarlığı öğrencileri için kentsel açık mekanlarda da en çok kullanılan donatı yani oturma birimi tasarım sürecini öğrenmek önemlidir. Oturma etkinliği yer düzleminde gerçekleşebileceği gibi, yüksekliği olan bir donatıda da gerçekleşebilir. Oturma donatısı mekanın verilerine, işlev ve amacına göre tasarlanmalıdır (Keegan, 1962). Ancak kullanıcın fiziksel ölçüleri bellidir ve mekansal özellikler ne olursa olsun antropometrik ölçüler ilk olarak sağlanması gereken özelliklerdir (Altıparmakoğulları, 2009). Tasarımcıya düşen ilk olarak ergonomik, ikinci olarak da özgün, yaratıcı oturma birimleri tasarlamaktır (Casakin, 2007; Çubukçu ve Gökçen Dündar, 2007; Düzenli vd., 2017a; Mumcu vd., 2016).

Peyzaj Mimarlığı eğitiminde öğrencilerin sistematik ve özgün tasarımlar ortaya koymaları beklenmektedir çünkü peyzaj mimarları çok boyutlu düşünebilmelidir (Özkan vd., 2016; Yılmaz vd., 2016; Düzenli vd., 2017c). Donatı tasarımı eğitimi de bu yaratıcı sürecin bir parçasıdır ve amacı etkinliğe uygun ölçü ve biçimde özgün donatılar tasarlamayı öğretmektir. Bundan dolayı öğrenciler oturma donatıları tasarlarken pek çok farklı durumu değerlendirmelidir. Donatının ölçüleri, biçimi, dokusu yani tüm estetik ve fonksiyonel özellikler bunlardan bazılarıdır. Karadeniz Teknik Üniversitesi (KTÜ) Peyzaj Mimarlığı Bölümünde de öğrencilerin tasarım ve yaratıcılık becerilerini geliştirmek amacıyla usta çırak ilişkisiyle yürütülen teorik ve uygulamalı stüdyo dersleri çok önemlidir. Donatı Tasarımı dersi de bu açıdan önemli bir derstir. Çalışmada Peyzaj Mimarıığı bölümü eğitiminde donatı tasarımını özgün-yaratıcı bir şekilde kurgulatmayı hedefleyen "Donatı Tasarımı" dersinde üretilen oturma donatıları ele alınmıştır. Bu bağlamda çalışmada Peyzaj Mimarlığı bölümü eğitiminde ergonomik ve özgün donatılar tasarlatmayı amaçlayan Donatı Tasarım dersinde yapılan oturma birimi maketleri değerlendirilmiştir.

\section{2. ÇALIŞMANIN ÖNEMI (RESEARCH SIGNIFINCE)}

Çalışmanın önemi; tasarımların başarıya ulaşılmasını amaçlayan, kullanıcı ihtiyaçlarına uygun donatılar tasarlamayı öğretmeyi teşvik eden özgün bir araştırma oluşudur. Kullanıcı beklentilerine cevap verecek uygun ölçü ve biçimde, mekânın kimliğiyle uyumlu donatıların tasarlanmasını öğretmeyi amaçlamaktadır. Çalışmada incelenen donatıların, biçim ve işlevinin mekân ile uyumlu ve özgün olması önemsenmiştir. Ayrıca incelediği donatı eğitim yaklaşımının; tasarım öğrencilerine estetik, işlevsel ve yaratıcılık açısından yardımcı olduğu ortaya konarak donatı tasarım eğitimini daha anlaşılabilir hale getirilmesi hedeflenmiştir. 


\section{MATERYAL VE YÖNTEM (MATERIALS AND METHODS)}

Bu çalışmada öğrencilerin sonuç ürün maketleri ölçü-biçimyaratıcılık açısından değerlendirilmiştir. Bu çalışmanın materyalini ise, KTÜ Peyzaj Mimarlığı Bölümü 2017 yılı 3. yarıyıl derslerinden "Donatı Tasarımı" dersinde öğrenciler tarafından tasarlanan 1/20 ölçekli oturma birimi maketleri oluşturur. Peyzaj mimarlarının amacı; insanların ihtiyaç ve isteklerini karşılayabilmek için uygun mekanlar tasarlayabilmektir. Peyzaj mimarlığı disiplininde bu mekanların tasarım kriteri hem fonksiyonel hem de yaratıcı tasarımlar ortaya koyabilmektir. Bu nedenle bu derste, öğrencilerin seçilen etkinlik için uygun ölçü, malzeme ve biçimde özgün donatılar tasarlayabilmesi amaçlanmaktadır. Yani bu ders kapsamında öğrenciler, öncelikle donatı elemanlarının kullanım amaçları, türleri, ölçüleri, mekansal kurgusu, vb. konularda bilgi alırlar. Daha sonra dünyadaki tasarlanmış donatı örnekleri mekan-donatı ilişkisi açısından detaylı olarak araştırılır. Dersin sonraki aşamalarında dersi alan 37 öğrenciden oturma etkinliği için maket üzerinde 1/20 ölçeğinde donatı tasarlamaları istenir. Amaç oturma donatısını uygun ölçü ve özgün biçimde nasıl tasarlanabileceğinin öğrenciye kavratılmasıdır. Bu dersteki eğitim yaklaşımı, biçimsel ve işlevsel bütünlüğün bir arada sağlanmasını amaçlar. Öğrencilerden seçilen oturma etkinliğine göre yorumlayarak doğru ölçü ve biçimde özgün oturma birimi tasarlamaları ve bunu maketle ifade etmeleri beklenir.

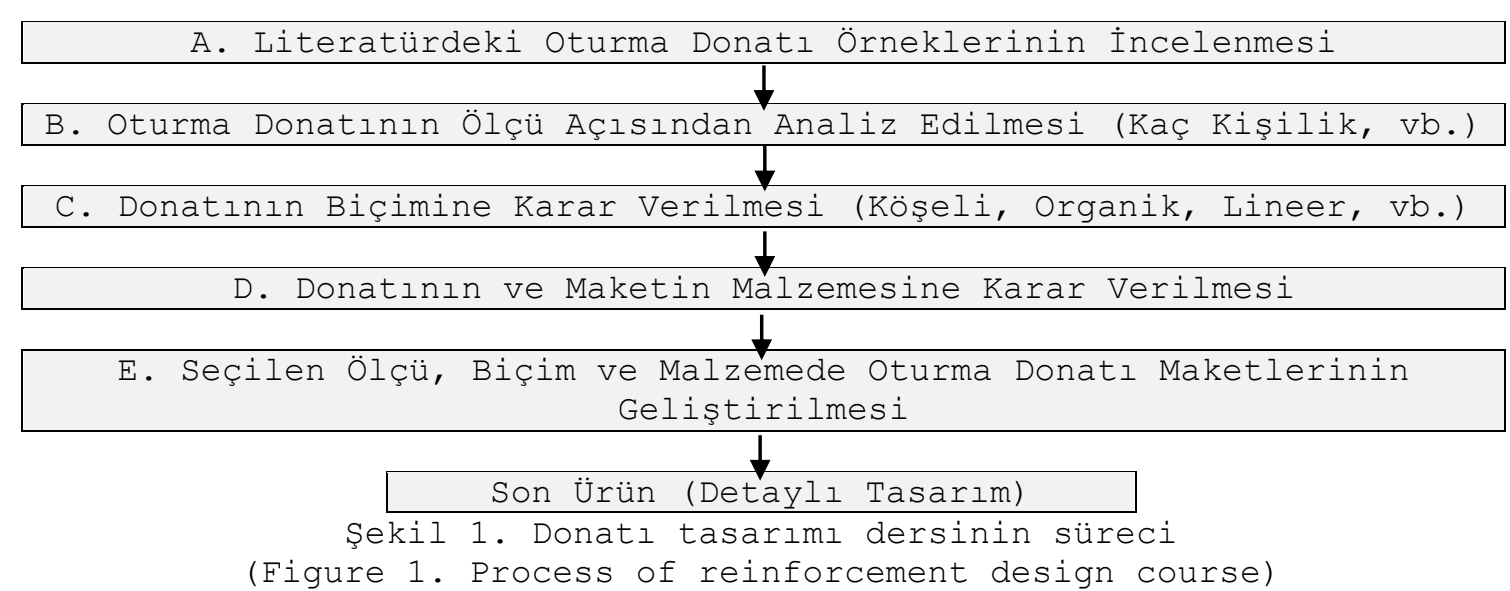

Doğrudan maket tekniği üzerinden örgütlenen derste, maketle
düşünmek, araştırmak, kurmak, denemek, tasarlamak hedeflenmiştir. Malzeme serbest bırakılmış, öğrencinin hayal ettiği biçime uygun malzemeyi seçmesi, malzemenin doğasına uygun tekniği bulması dolayısıyla malzeme-biçim uyumunu arttırmaya yönelik denemeler yapması da sağlanmıştır. Öğrenciler ilk aşamada literatürdeki soyut-somut donatı örneklerini inceleyerek makette seçecekleri biçime karar verirler. Böylece kendi çalışmalarında kullanacakları özgün karakter seçilir. Öğrenci bu aşamada literatür taramasından elde ettikleri fikirleri üç boyutlu maket çalışmalarına aktarmaya başlarlar. 6 haftalık süreç boyunca ders sorumlusunun eleştirileri doğrultusunda maket gelişerek değişir. Süreç sonunda sıra dışı, yaratıcı, ergonomik ürüne ulaşılır. Ulaşılan yaratıcı özgün $1 / 20$ ölçekli oturma birimi maketi sonuç ürün olarak teslim edilir (Şekil 2). 

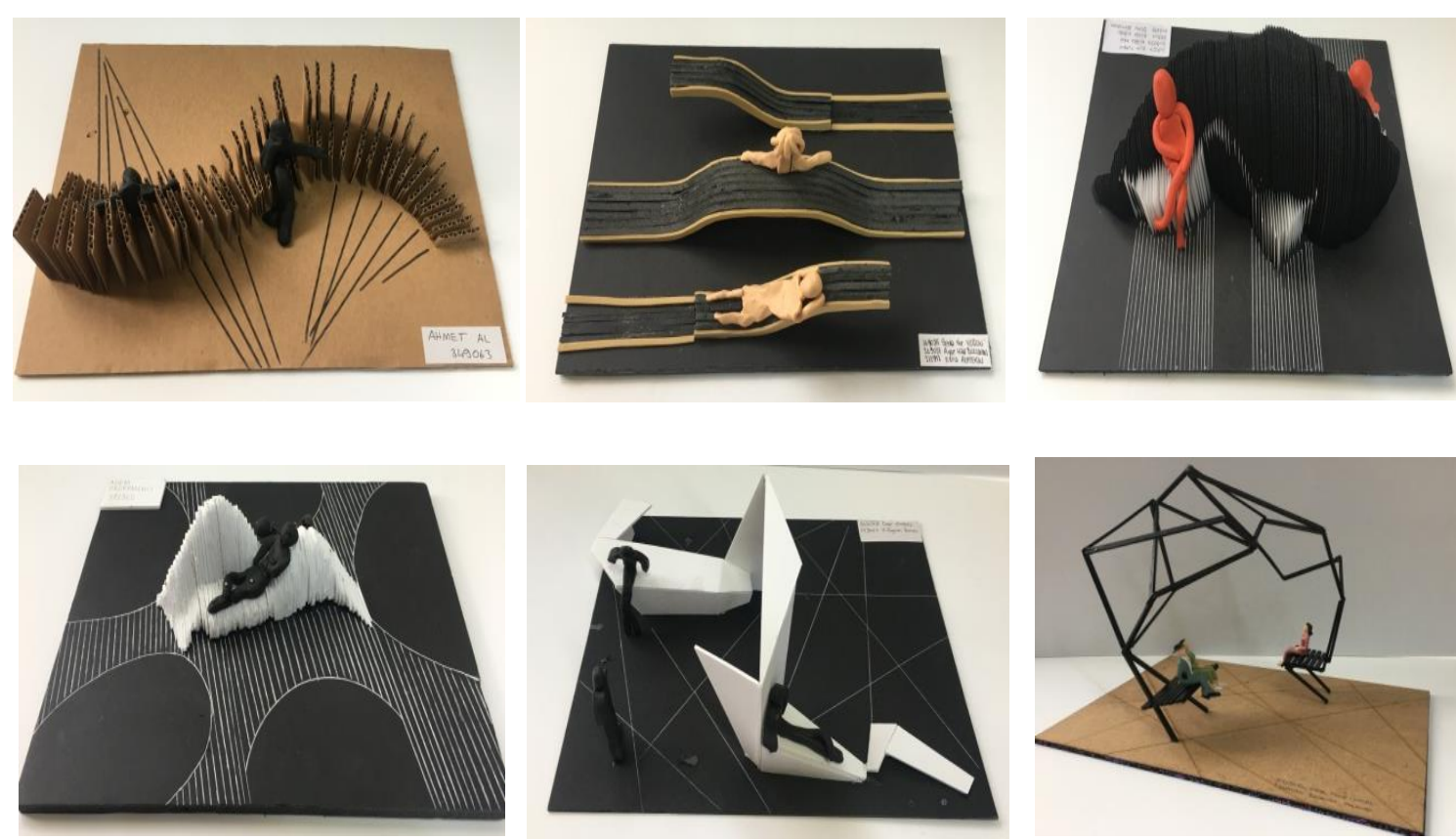

Şekil 2. Ders kapsamında yapılan oturma birimi maketleri (Figure 2. Ders kapsamında yapılan oturma birimi maketleri)

\section{BULGULAR VE TARTIŞMA (FINDINGS AND DISCUSSION)}

2017 yılında bu ders kapsamında öğrencilerin yaptığı oturma birimi maketlerinde; ölçü-biçim-yaratıcılık çözümleri analiz edilmiştir. Öğrencilerin oturma etkinliği için 1/20 ölçeğinde maket boyutunda oturma donatısı tasarlamaları istenmiştir. Yapılan öğrenci maketleri: ölçü-biçim-yaratıcılık açısından Tablo $1^{\prime}$ de incelenmiştir. 2017 yılında bu ders kapsamında öğrencilerin yaptığı oturma birimi maketlerinde; ölçü-biçim-yaratıcılık çözümleri analiz edilmiştir. Öğrencilerin oturma etkinliği için 1/20 ölçeğinde maket boyutunda oturma donatısı tasarlamaları istenmiştir. Yapılan öğrenci maketleri: ölçü-biçim-yaratıcılık açısından aşağıdaki örneklerde incelenmiştir.

\section{Nolu Çalışma:}
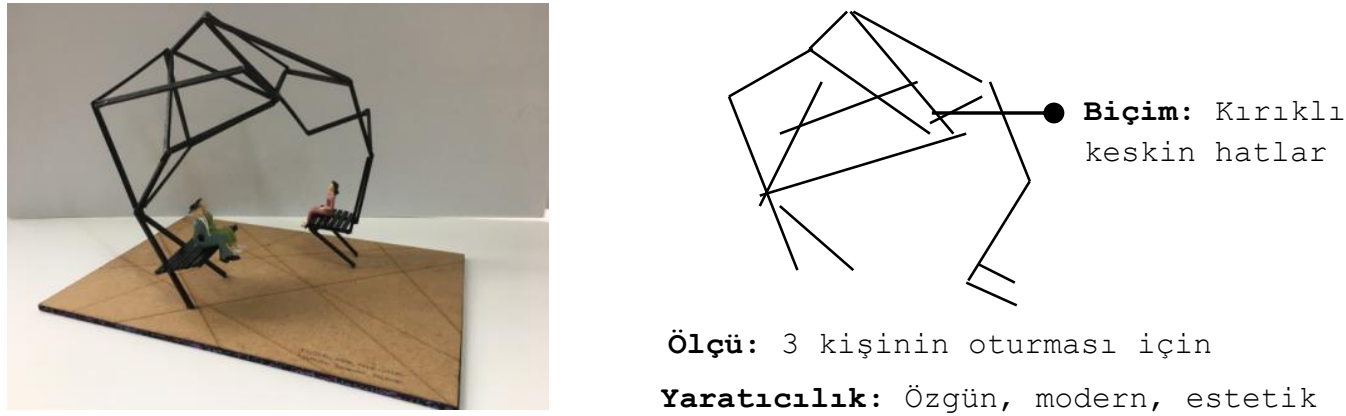

ölçü: 3 kişinin oturması için

Yaratıcılık: Özgün, modern, estetik

- Birinci Çalışma: Bu çalışmada öğrenci 2-3 kişinin oturması ve sallanmasına imkân sağlayan kırıklı keskin hatlara sahip, yer döşemesiyle uyumlu, üzerinde estetik bir örtü elemanıyla bütünleşen yaratıcı bir oturma donatısı tasarlamıştır. Öğrenci donatıyı; Çevre Tasarım Proje dersindeki birkaç konut çevre düzenlemesi projesinin ortak kullanım alanında yer almak üzere tasarlamıştır. Mekan köşeli hatlara ve kırıklı döşemelere sahip, 
oturma-dinlenme amaçlı bir yerdir. Dolayısıyla donatı kullanılacağı mekanla hem biçimsel hem fonksiyonel açıdan uyumludur.

2 Nolu Çalışma:

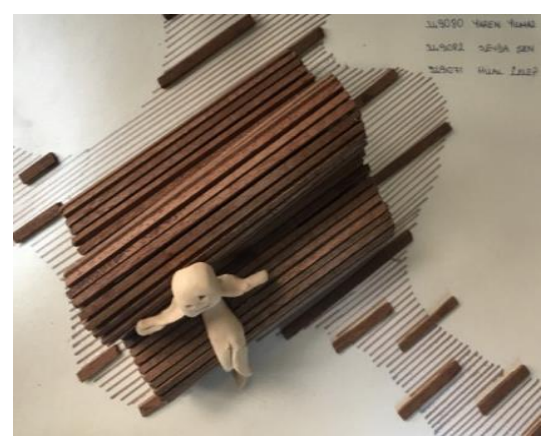

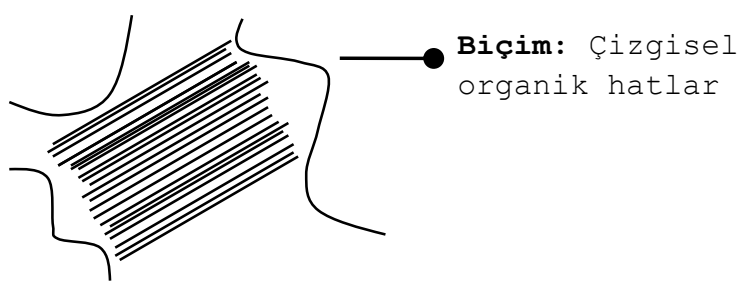

Ölçü: 6 kişinin oturması için

Yaratıcılık: Özgün, geleneksel, estetik

- İkinci Çalışma: Bu çalışmada öğrenci 6 kişinin önlü arkalı oturmasına imkân sağlayan, çizgisel organik hatlı yer döşemesiyle uyumlu, ahşap geleneksel ve estetik bir oturma donatısı tasarlamıştır. Donatıyı yerleştireceği mekan bir kent parkıdır. Sirkülasyona ve etkinliğe uyumlu, mekanla bütünleşen bir donatı tasarlamıştır.

3 Nolu Çalışma:
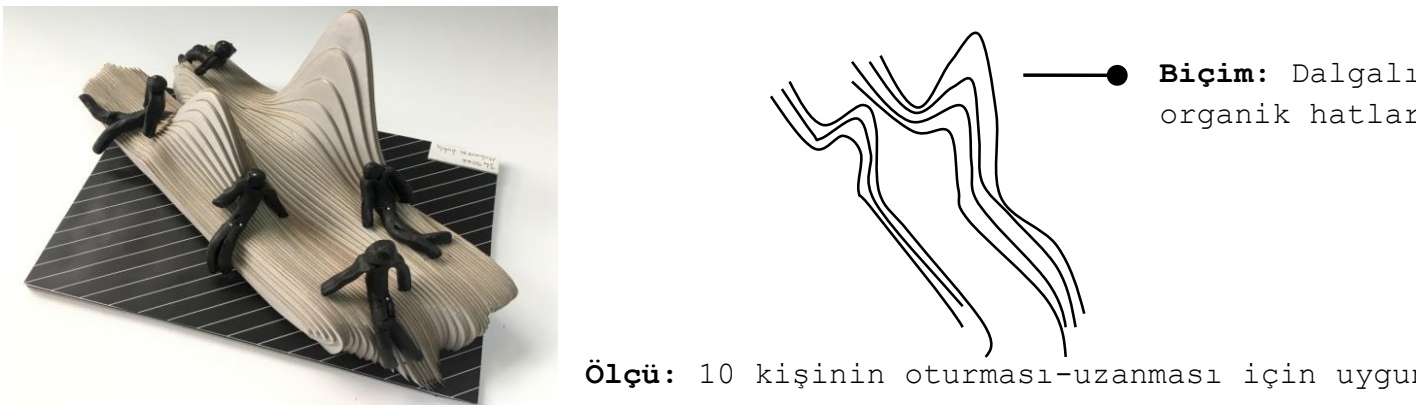

Ölçü: 10 kişinin oturması-uzanması için uygun

Yaratıcılık: Özgün, modern, estetik

- Üçüncü Çalışma: Bu çalışmada öğrenci 8-10 kişinin oturmasına, uzanmasına, oyun oynamasına imkân sağlayan, dalgalı organik hatlara sahip, yer döşemesine zıt biçimde yerleştirilmiş, kentsel obje olarak da dikkat çekebilecek özgün ve modern bir oturma donatısı tasarlamıştır. Donatının; çocukların yoğun olarak kullandığı bir kent avlusunda kullanılması amaçlanmıştır. Çizgisel sirkülasyona sahip bu mekana biçimsel olarak uyumludur. Ayrıca çocukların hareketıi yapısıyla örtüşen, oyun etkinliklerine olanak sağlayan bir donatıdır. 

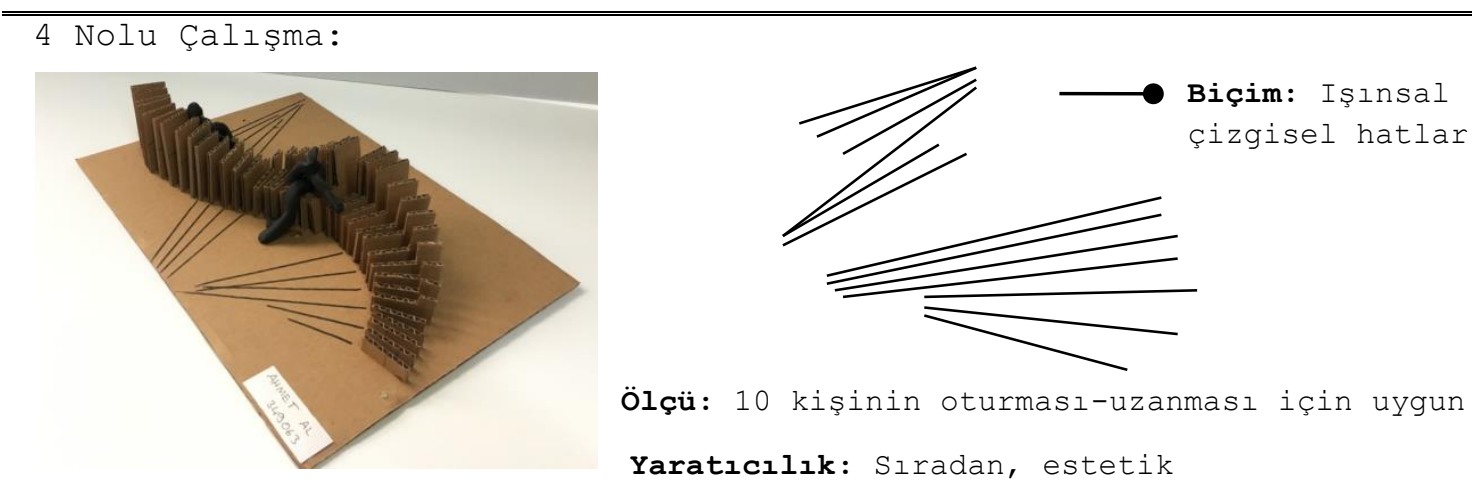

Ölçü: 10 kişinin oturması-uzanması için uygun

Yaratıcılık: Sıradan, estetik

- Dördüncü Çalışma: Bu çalışmada öğrenci 10 kişinin önlü arkalı oturmasına imkân sağlayacak, çizgisel ışınsal hatlara sahip, sıradan ancak estetik bir oturma donatısı tasarlamıştır. Bu donatının bir kamusal mekanın beklemeye yönelik bahçesinde kullanılması amaçlanmıştır. Hem bekleme etkinliğiyle hem de resmi kurumun biçimiyle özdeşleşmektedir. Resmi bir mekana hizmet ettiğinden sıradan bir biçim tercih edilmiştir.

5 Nolu Çalışma:
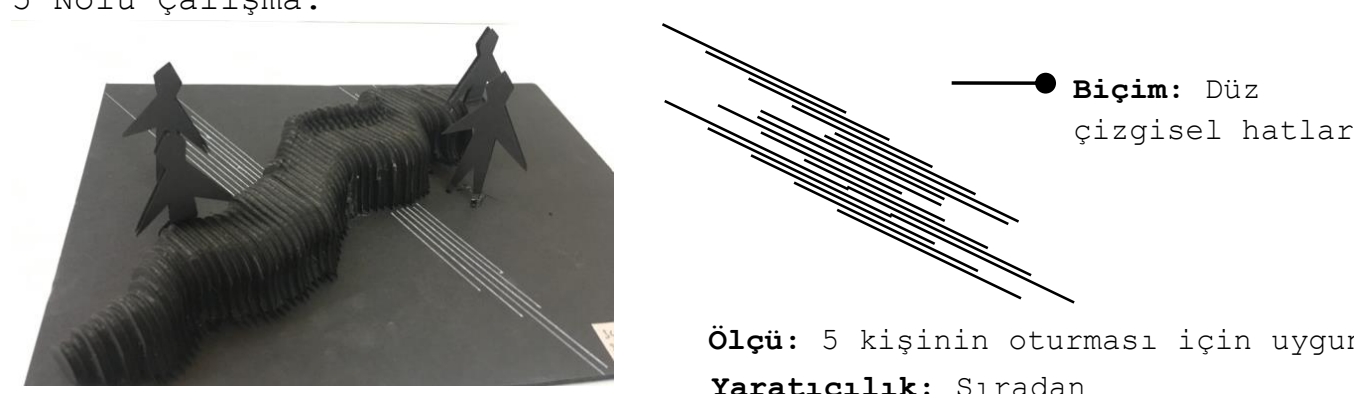

Ölçü: 5 kişinin oturması için uygun

Yaratıcılık: Sıradan

- Beşinci Çalışma: Bu çalışmada öğrenci 5 kişinin yan yana oturmasına imkân sağlayacak, çizgisel düz hatlara sahip, sıradan bir oturma donatısı tasarlamıştır. Kullanılacağı mekan bir durak olduğundan işlevi ve biçimi uygundur.

6 Nolu Çalışma:

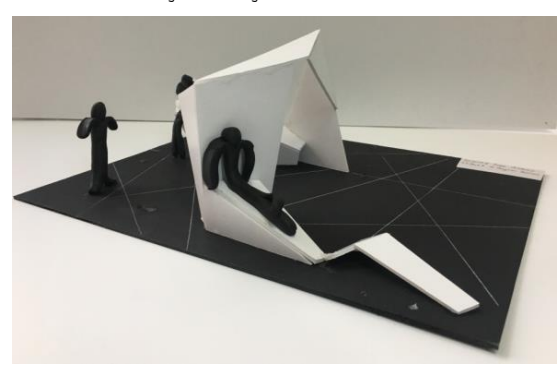

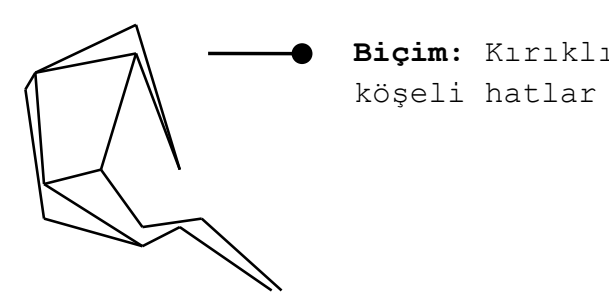

ölçü: 3 kişinin oturması, uzanması için

Yaratıcılık: Özgün, modern, estetik

- Altıncı Çalışma: Bu çalışmada öğrenci 3 kişinin oturması ve uzanmasına imkân sağlayan kırıklı köşeli hatlara sahip, yer döşemesiyle uyumlu üzerinde estetik bir örtü elemanıyla bütünleşen yaratıcı bir oturma donatısı tasarlamıştır. Bir kent meydanında kullanılması amaçlandığından, heykel, örtü ve oturma gibi işlevler bir arada tasarlanmış, böylece mekana uyum sağlanmıştır. 
7 nolu Çalışma:
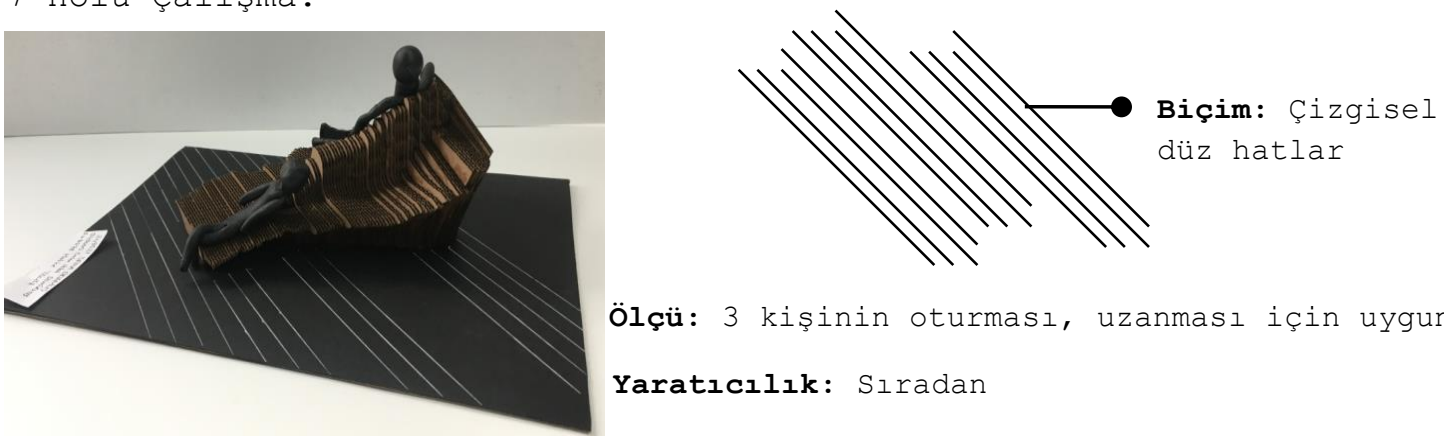

ölçü: 3 kişinin oturması, uzanması için uygun

Yaratıcılık: Sıradan

- Yedinci Çalışma: Bu Çlışmada öğrenci 2-3 kişinin oturması ve uzanmasına imkân sağlayan çizgisel düz hatlara sahip, yer döşemesiyle uyumlu sıradan bir oturma donatısı tasarlamıştır. Bu donatı bir toplu konutun bahçesinde kullanılmak üzere tasarlandığından; mekanın çizgisel hatları ve dinlenme fonksiyonu ile uyumludur.

Kullanıcı ihtiyaçlarına uygun donatılar tasarlamak kullanışlı yaşayan mekanlar yaratmanın bir parçasıdır (Jordan ve Green, 1999; Siu, 2005; Siu, 2009; Prudhomme ve ark., 2003,). Çünkü tasarım yalnızca fiziksel bir süreç değil aynı zamanda kullanıcının tercihleri ve ihtiyaçlarını da içeren psikososyal bir süreçtir (Clarkson vd., 2004, Siu 2007; Düzenli vd., 2017b). Bu nedenle kullanıcı ihtiyaçlarını karşılayan uygun ölçü ve biçimde, mekânın kimliğini yansıtan donatılar tasarlamak gereklidir. Yaratılan tasarımda donatının biçimi ve işlevi mekân ile uyum sağlarken aynı zamanda özgün-yaratıcı da olmalıdır. Yapılan tüm öğrenci maketleri incelendiğinde öğrencilerin biçimsel açıdan farklı yaklaşımlarda bulunduğu, kırıklı-düz-organik vb. farklı hatları kullandıkları, ölçü açısından da farklı yaklaşımları olduğu kiminin 2-3 kişilik, kiminin kalabalık gruplara hitap eden oturma birimleri tasarladığı, kiminin daha yaratıcı ürünler ortaya koyarken kiminin daha sıradan bir tarzı benimsediği belirlenmiştir. Bazı tasarımların modern bazılarının daha geleneksel olduğu da görülmüştür.

\section{SONUÇ VE ÖNERILER (CONCLUSION AND RECOMMENDATIONS)}

Bu çalışmada oturma donatılarının işlevsel ve estetik olarak kurgulanmasını amaçlayan donatı tasarımı dersinin yararları belirlenmiştir. Bu derste;

- Öğrenciler farklı biçime, farklı ölçülere ve yaratıcılığa sahip oturma donatı maketleri yapmışlardır.

- Oturma donatıları tasarlanırken, işlevsel kurguyla ve estetik kurgu bir arada sağlanmaya çalışılmıştır.

- Bu eğitim yaklaşımı; tasarım öğrencilerinin yaratıcılıklarını geliştirmiş, estetik, işlevsel açıdan onlara yardımcı olmuş ve donatı tasarım eğitiminin öğreticiliğini de arttırmıştır.

- Öğrencilerin; oturma donatılarının ölçülerini öğrendikleri görülmüştür.

- Öğrencilerin tasarım yaklaşımları gelişirken, kulıanıcı ihtiyaçlarına cevap veren mekan kimliğiyle uyumlu oturma donatısı tasarım bilinci kazanmıs çevresel tasarımcıların yetiştirilmesinde de fayda sağlamaktadır.

Öğrencilerin ilgi alanlarına bağlı olarak ve konuyla ilgili alınacak başka derslere göre tasarım ile yaratılan mekân-donatı 
ilişkisi ve donatı çeşidi arttırılabilir. Böylece tasarımcı-öğrenci, seçtiği etkinliğe ve mekâna yönelik uygun, kullanıcı ihtiyaçlarını karşılayan, yaratıcı donatı tasarımları yaratabilir.

\section{NOT (NOTICE)}

$\mathrm{Bu}$ çalışma ISAS 2018 1st International Symposium on Recent Advances in Vocational Sciences kongresinde sözlü bildiri olarak sunulmuş ve yeniden yapılandırılmıştır.

\section{KAYNAKLAR (REFERENCES)}

- Altıparmakoğulları, Y., (2009). Oturma Öğesi Tasarımında Basınç Diyagramı Modelinin Kullanılmasıyla Oturma Profilinin Tasarım Kriterlerinin Ortaya Konması. Yüksek Lisans Tezi, Mimar Sinan Güzel Sanatlar Üniversitesi, Fen Bilimleri Enstitüsü.

- Bayraktar, N., Tekel, A. ve Ercoşkun Yalçıner, Ö., (2008). Ankara Atatürk Bulvarı Üzerinde Yer Alan Kentsel Donatı Elemanlarının Sınıflandırılması, Değerlendirilmesi ve Kent Kimliği İlişkisi. Gazi Üniversitesi Müh. Mim. Fakültesi Dergisi, Cilt:23, No:1, ss:105-118.

- Casakin, H.P., (2007). Factors of Metaphors in Design ProblemSolving: Implications for Design Creativity. International Journal of Design, 1:21-33.

- Celbiş, Ü., (2001). Ürün Kullanıcı İlişkileri Bağlamında Kent Mobilyaları ve İşlevleri. Türkiye I. Uluslararası Kent Mobilyaları Sempozyumu, İstanbul, ss:175-178.

- Clarkson, P.J., Buckle, P., Coleman, R., Stubbs, D., Ward, J., Jarrett, J., Lane, R., and Bound, J., (2004). Design for Patient Safety: A Review of the Effectiveness of Design in the UK Health Service. J. Eng. Design, 15(2):123-140.

- Çubukcu, E. and Gökçen Dündar, Ş., (2007). Can Creativity be Taught? An Empirical Study on Benefits of Visual Analogy in Basic Design Education, ITU A|Z Vol:4 No:2, pp:67-80.

- Düzenli, T., Yllmaz, S., and Alpak, E.M., (2017a). The Effects of Model Making on Design and Learning in Landscape Architecture Education, Eurasian Journal of Educational Research, Vol:17, pp:121-134.

- Düzenli, T., Yllmaz, S. ve Özkan, D.G., (2017b). Peyzaj Mimarlığı Eğitiminde Donatı-Mekân İlişkisinin Kurgulanması Building The Relationship between Furniture-Space in The Education of Landscape Architecture, The Journal of International Social Research, Vol:10, pp:478-485.

- Düzenli, T., Mumcu, S., Özkan, D.G., Alpak, E.M., (2017c). Peyzaj Mimarlığı Eğitiminde Kentsel Obje Tasarımlarının Sanatsal Açıdan İncelenmesi, Sed Sanat Eğitimi Dergisi, Vol:5, pp:.57-68.

- Güney, A., Erdem, Ü., Zafer, B., and Hepcan, \$̧., (1996). Peyzaj Konstrüksiyonu (Donatı Elemanları). Ege Üniversitesi Ziraat Fakültesi Yayınları, (514).

- Harris, C.W., Dines, N., Brown, T., and Kyle, D., (1998). TimeSaver Standards for Landscape Architecture: Design and Construction Data, Second Edition, McGraw-Hill Publishing Company.

- Jordan, P.W. and Green, W.S., (1999). Human Factors in Product Design: Current Practice and Future Trends. Taylor and Francis, London.

- Keegan, J.J., (1962). Evaluation and Improvement of Seats, Industry Med. Surg. 31:137-148. 
- Molnar, D., (2015). Anatomy of a Park. 3rd Edition, Waveland Press, Long Grove, Ilionis. 210.

- Mumcu, S., Yilmaz, S. ve Düzenli, T., (2017). Açık Mekanlardaki Oturma Donatılarının ve Yerlerinin Tasarımına İlişkin Faktörler, İnönü Üniversitesi Sanat ve Tasarım Dergisi, Cilt:7, ss:1-16.

- Özkan, D.G., Alpak, E.M. ve Düzenli T., (2016). Tasarım Eğitiminde Yaratıcılığın Geliştirilmesi: Peyzaj Mimarlığı Çevre Tasarımı Stüdyo Çalışması IJASOS- International E-Journal of Advances in Social Sciences, 136-143.

- Prudhomme, G., Zwolinshi, P., and Brissaud, D., (2003). Integrating into the Design Process the Needs of Those Involved in the Product Life-cycle. J. Eng. Design, 13(3):333-353.

- Siu, K.W.M., (2005). Pleasurable Products: Public Space Furniture with Userfitness, Journal of Engineering Design, $16(6): 545-555$.

- Siu, K.W.M., (2007). Guerrilla Wars in Everyday Public Spaces: Reflections and Inspirations for Designers, International Journal of Design, 1(1): 37-56.

- Siu, K.W.M., (2009). Public Design for Changing Urban Needs, Korean Society of Design Science, Seul, 3085-3093.

- Yıldırım, K., (2000). Konut Mutfakları ile Ergonomik Bir Araştırma, G.ü., Fen Bilimleri Enstitüsü Dergisi, 13, 549-567.

- Yilmaz, S., Mumcu, S., Düzenli, T., Özbilen, A., (2016). Analyzing The Unity Concept İ Design On Student Works: A Case Study of Architectural Design Course, Inonu University Journal Of Art and Design, Vol:6, ss:1-12.

- Yücel, G.F., (2006). Kamusal Açık Mekanlarda Donatı Elemanlarının Kullanımı. Ege Mimarlık, 26-29. 